\title{
Evaluation of the Technical Condition of Auger Equipment Units by Vibration Inspections
}

\author{
Mametyev Leonid E., Drozdenko Yuriy V.a, Lyubimov Oleg V. . \\ T. F. Gorbachev Kuzbass State Technical University \\ Kemerovo, Russian Federation \\ avd11@ rambler.ru; boleg_lyubimov@mail.ru
}

\begin{abstract}
The article describes the design and operational factors leading to failures in mounting groups of the modern auger equipment. At the same time, the operating experience was considered of using antifriction bearings with solid lubricant antifriction filler (AFZ) having self-lubricating and self-sealing properties in various mounting groups. The changes in bearing clearances with AFZ as potential sources of high-frequency oscillations were assessed, also potential sources of low-frequency high-amplitude oscillations were identified in the design. As a result, the impact of mounting groups of the auger equipment on the change of the availability condition in the process of performance was assessed using vibration-based diagnostics method. The design of the mounting group with AFZ without end covers was proposed. Application of such a mounting group increases the service life of bearing support in the areas inaccessible for maintenance and repairs resulting in reduced labor intensity, energy and financial costs.
\end{abstract}

Keywords-auger equipment; mounting group; technical condition; vibration inspection.

\section{INTRODUCTION}

Extension of the scope of modern mining equipment includes a solution of vital problems of some industries. Of particular importance modern tunneling technology and equipment are for the mining, oil, gas and construction industries [1-7].

The process of operation of the equipment is associated with the change of its technical condition and a fault detection and removal of which involves considerable investment of time and financial resources. In this situation, special importance is the process of diagnosis and identification of its residual life [8-10].

A set of interrelated design and operational factors has an influence on the quality of the forecast for operating condition of auger equipment's units during vibration surveys in its operation.

In confirmation of this, at an early stage at the T.F. Gorbachev Kuzbass State Technical University in the departments of mining machines and systems and information and automated production systems, the operational experience was gained in mounting groups for various purposes equipped with ball bearing designs with the solid lubricating antifriction filler (AFZ). They are carried out on the basis of standard ball bearings by filling the free internal space with pasty antifriction compound followed by curing, the formation of clearances between the cured filler and subsequent runningbearing parts [11].

The main advantage of this type of bearings making them different from other technical solutions in this area, is the selflubrication and simultaneous execution of the self-sealing of the friction zone defined by small clearances between the cured AFZ and the bearing rings. In fact, the AFZ performs the function of the double slit up-compacting, which actualizes the use of bearings of this type, for example, in mounting groups screw units of horizontal boring machine (fig. 1), unattended into the space of bored well, especially when installing wells with moistening of bored products [12].

Due to the fact that the increase in size of the clearance in the bearing with the AFZ in the operation, as well as any wear process refers to phenomena more difficult to describe analytically using parametric complexes appeared-one to appropriate its experimental study with subsequent reliability checking of the results.

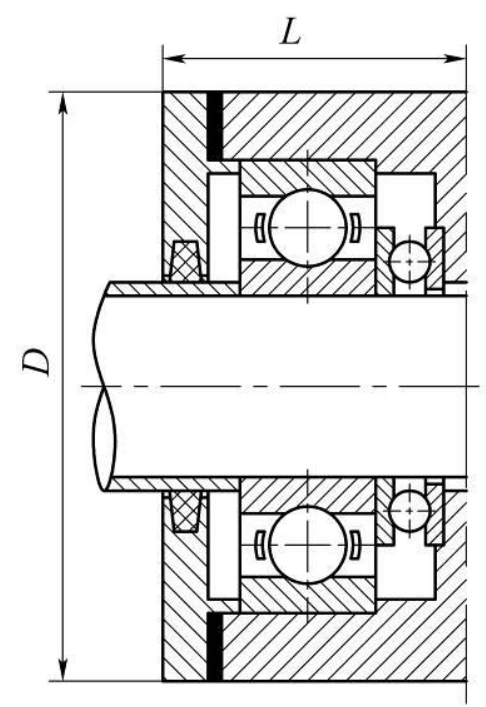

a

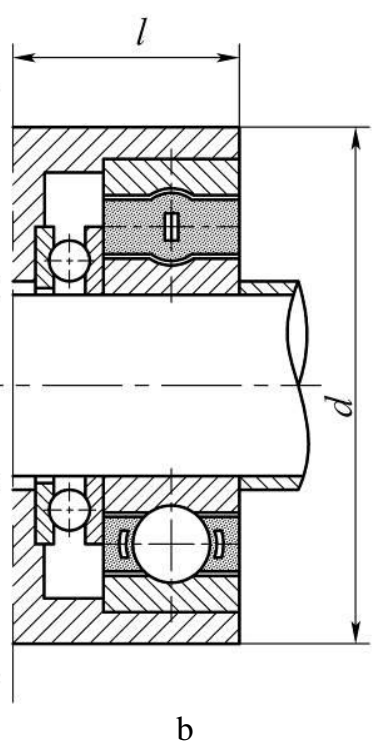

$\mathrm{b}$
Fig. 1. Comparative dimensions of the screw support units of augers: (a) with standard bearings; (b) with AFZ bearings 


\section{MATERIALS AND METHODS}

Hours bearing life was carried out on a test machine CDB72. With a view to the protection of the solid filler from the oil pollution, as well as providing a natural for this type of bearing the heat sink the hydraulic system of loading and lubrication of the bearings was replaced by a system of loads and lever arms with variable length. The values of fixed radial load during the experiment were taken to be its own weight of the bearing unit of the testing machine in increments of $0 \ldots$ $7000 \mathrm{~N}$ in conditions of non-transition on the other bearing failure criteria, other than the principal. Construction of the test head and the main shaft housing changed in such a way as to ensure ease of visual observation and quick release bearings for the second periodic non-destructive testing.

For non-destructive testing changes in size of the clearance in the process of use of the resource used X-ray method, a block diagram is shown in fig. 2a. It is based on the weakening of the intensity of X-rays in passing through the bearing controlled. This provides the documentary control.

The radiation produced by the source 1 and directed from the opening of the glove box 2 X-ray machine RUP-200-5-2, passes through the test bearing 5 marks 6,7 and sensitivity of standard-recorded photograph graphically on X-ray film such as RT-5, contained in cassette 8 . The quality of the X-ray image is controlled by the signal transmission X-ray's vidicon
9 type LI-423 via the amplification unit 10 and the scanner 11 on the screen 13 of X-ray television complex PTU-39. The radiation intensity is regulated by gate 3 and a filter 4 . To protect the operator and the environment from the harmful effect of radiation is provided biological protection 14 . The documents to be further investigated, is obtained X-ray 12.The intensity variation is expressed in changing the degree of photographic darkening areas of X-ray that integrate the incident radiation corresponding to the location of the test gaps.

Schematic diagram of the measurement values of the bearing clearances with AFZ on rent-diffraction patterns using a photometer IFO-451 is shown in fig. 2b. Power AC 6 of the photometer is set to a frequency modulation of the light beams, reinforcing the only variable component. Luminous flux from the source 1 is split into a measurement branch and reference branch. The light beam of the measuring branch consistently permeates the mask 3 , tapering analyzed band in surface precision Floating radiographs 2 and the movable photometric wedge 4 . The flows of both branches alternately pass through the cutouts in the disk sector-modulator 8 , a rotating actuator 9, falling on the photodetector 7 . If the streams are different, the circuit used in the anode photomultiplier FEU-17A fuss-repents ripple current, which leads through the amplifier 6 and the drive 5 to move the photometric wedge 4 and the automatic recorder pen 10 .
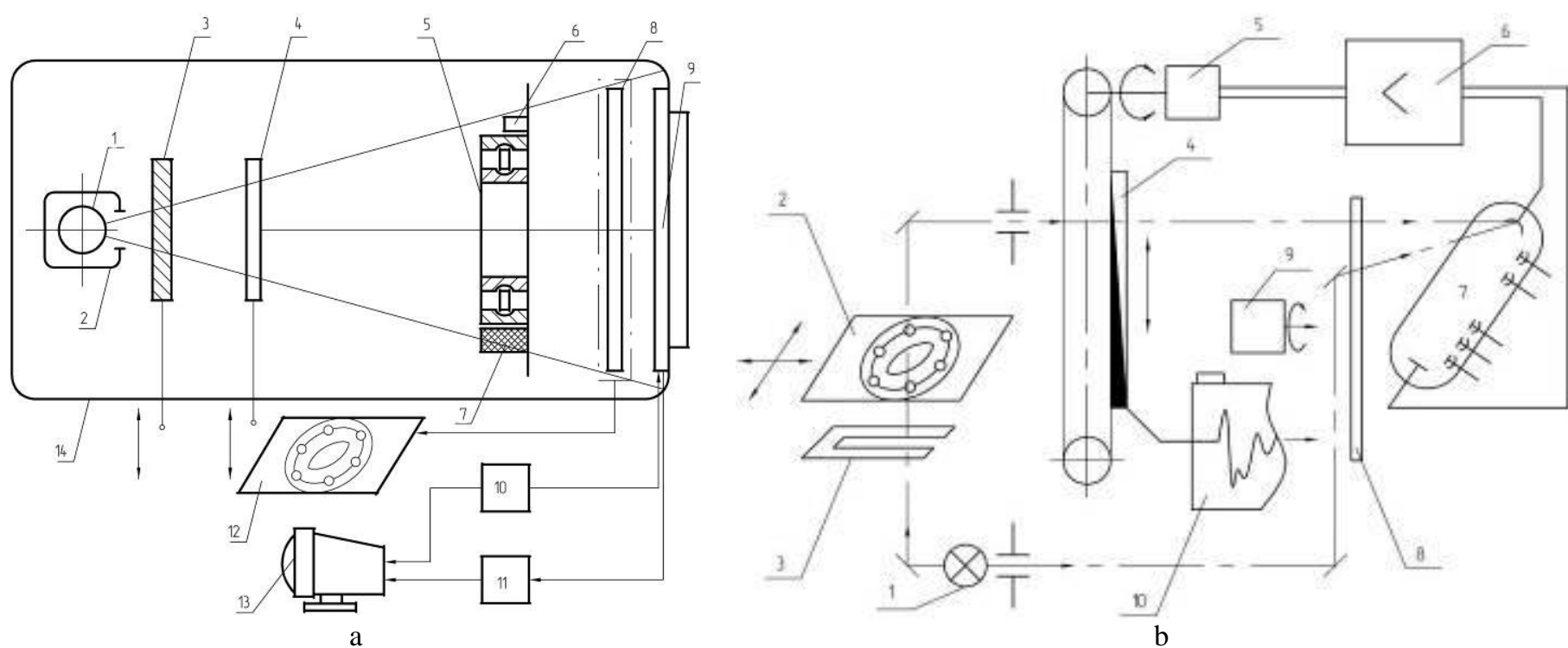

Fig. 2. The measurement of values of the bearing clearance with AFZ: (a) schematic diagram of the radiographic NDT method for size of the clearance; (b) schematic diagram of the measurement of values of clearance

Possibilities of wear processes were observed experimentally, in the form of polynomial regression models, the 3rd conducive to algebraically properties of these functions and their curves - the presence of specific areas that may reflect different intensities of wear condition of the absence of extremum of reflecting wear irreversibility of the process; lack of sloping area of the inflection point. Fig. 3 shows graphic interpretation of changes in the clearance between the AFZ and the inner ring and between the outer ring and the AFZ, depending on developments.
The above poster experiment and mathematical interpretation allowed to develop a model to predict the bearing clearances with AFZ as resource developments, having a form of polynomials of order 3 :

$$
\delta^{(k)}(L)=\delta_{0}^{(k)}+\sum_{i=1}^{3} b_{i}^{(k)}\left(\frac{P}{C}\right) \cdot L^{i}
$$

where $\delta_{0}^{(k)}$ - initial gap is based in section; $b_{i}^{(k)}(P / C)$ regression coefficients, which depend on the relative load. 


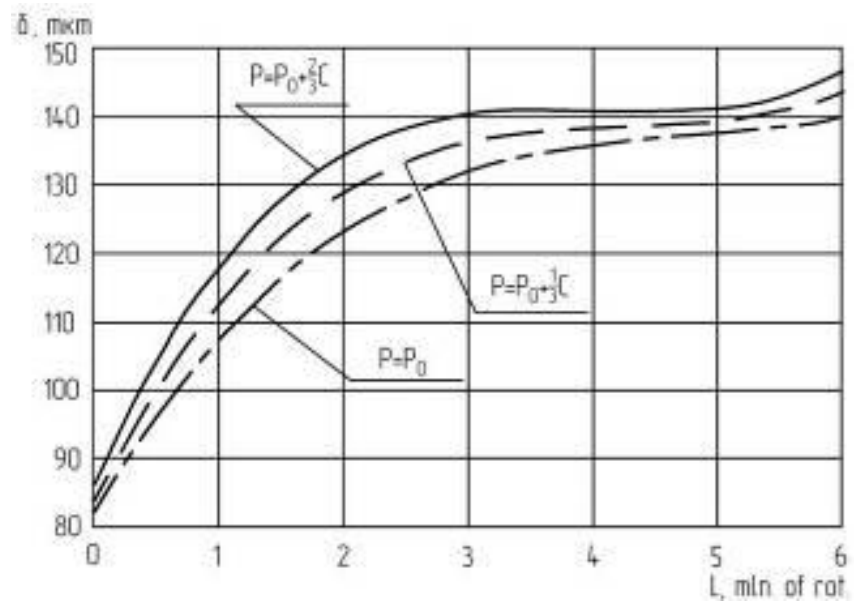

a

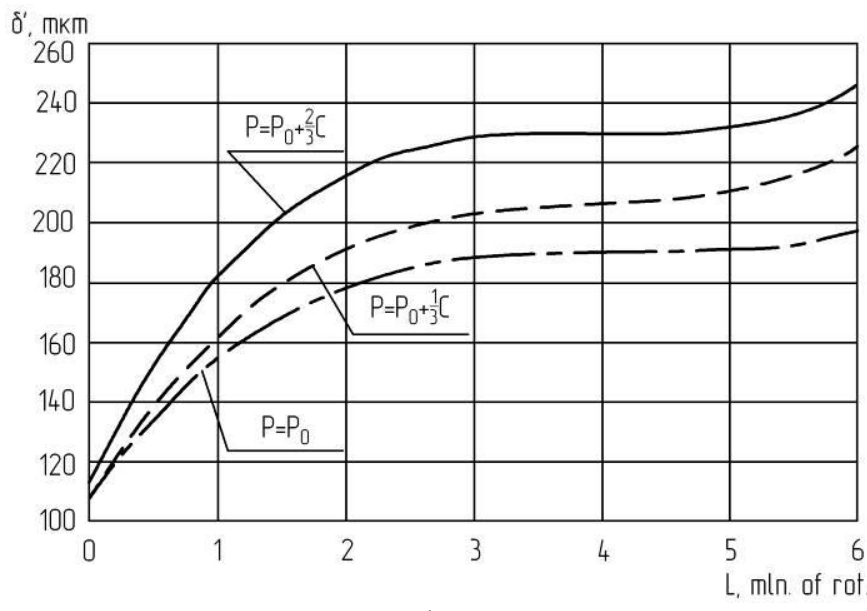

b

Fig. 3. Change in the clearances depending on the accumulated resource: (a) between the AFZ and the inner ring; (b) between the AFZ and the outer ring

Strict requirements to reduce radial and axial dimensions while simultaneously centering axis relative to the screw sections of the casing axis are presented to numerous support-centering bearing units (fig. 4a). Industrial tests of auger machine implemented in Kuzbass conditions showed that the drive unit

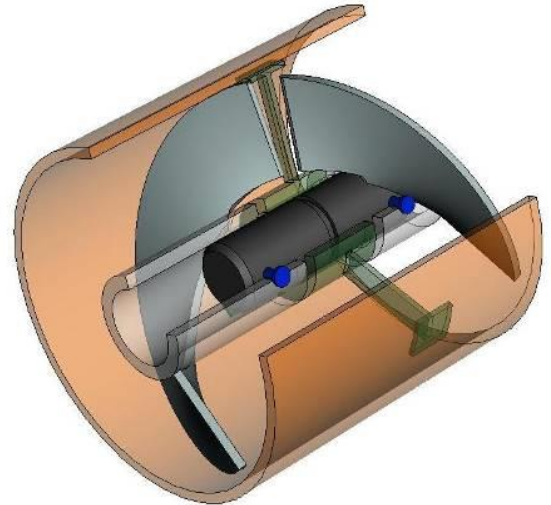

a equipped with standard ball bearings and radial seals does not meet the requirements, the gap between the device and the rays of the inner surface of casing string reaches $5 \mathrm{~mm}$. The situation is complicated by the large number of nodes on the data assembled screw put.

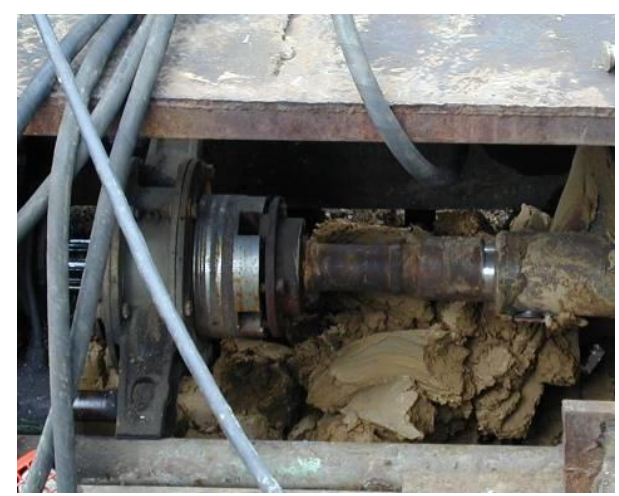

b

Fig. 4. Typical bearing units of auger equipment: (a) support-centering bearing unit; (b) traverse of the drill slip lock

Fig. $4 \mathrm{~b}$ is a perspective view of the slip yoke to drill the lock screw in the discharge zone of the composition of the drilling products.

Construction of these units on the basis of traditional common-engineering methods does not allow to avoid the appearance of clearances, leading to high-amplitude lowfrequency-oscillation processes in the system, especially under the pressure penetration in large quantity of moistened material drilled out.

The above species multiple sources of oscillations in systems lead to worst health indicators and the need for technical service. Further improvement of the auger equipment should be directed towards the fullest possible diagnosis of the state of its components and mechanisms.

\section{RESULTS}

To evaluate the technical condition and operational properties of the auger equipment set must be a comprehensive study of the mode of operation in an industrial environment in the operation of prototypes auger machines [13].

Control of the technical condition of support units is of particular importance for averting-rotation crashes. It is obvious that the systematic monitoring of their co-standing will allow for assessment of technical condition on the basis of quantitative criteria for assessing compliance with the level of vibration in the support-centering bearing units permissible levels [14]. Prevention of failures can be intermittent assistance, but the frequency of these works does currently not sufficiently substantiated. Therefore, the analysis of changes in the technical condition of the support units, based on the vibration data, provides the rationale for the timing of the 
preventive measures that help reduce the proportion of sudden failures. Control of vibration measured on bearing housings

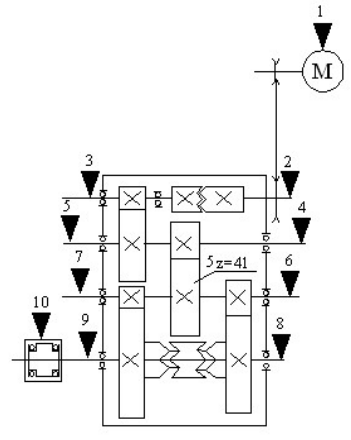

a of the unit in three mutually perpendicular directions: vertical, horizontal and axial (along the rotation axis), fig. 5.

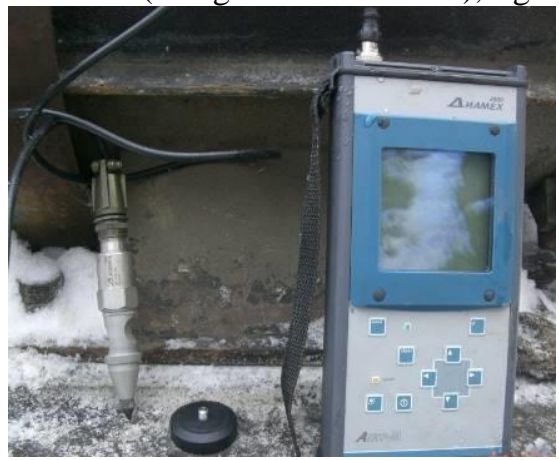

b

Fig. 5. Scheme of vibration measurement: (a) points on the gear rotator 2-9 - gear bearings, 10 - the bearing assembly tool joint;

(b) vibration analyzer «Agat-M»

The sensor is mounted so that its surface directly was operated by mechanical vibrations of the bearing. The sensor senses the mechanical vibrations of the bearing, with less impact vibration excited by the other nodes, and parts of the unit measurement of vibration on the thin-walled portion of the housing and covers unacceptable.

Frequency of control measures depends on the technicalstates of the object and set the order of diagnostic measurements.

In the process of carrying out diagnostic studies recorded the following parameters of vibration:

- rms vibration velocity ( $\mathrm{Ve}, \mathrm{mm} / \mathrm{s}$ ) bearing housings electric drive;

- peak acceleration gear bearing housings.

It is assumed that the parameters to be measured must be within the ranges given in Table 1.

TABLE 1.Control parameters of vibration-acoustic signal at the nodes auger machine

\begin{tabular}{|l|c|c|c|c|}
\hline \multicolumn{1}{|c|}{ Unit } & Parameter & $\begin{array}{c}\text { Frequency } \\
\text { range (Hz) }\end{array}$ & $\begin{array}{c}\text { Dynamic } \\
\text { range }\end{array}$ & $\begin{array}{c}\text { Measurement } \\
\text { error (\%), } \\
\text { not more }\end{array}$ \\
\hline $\begin{array}{l}\text { Electric } \\
\text { drive }\end{array}$ & $V_{e}$ & $10 \ldots 1000$ & $0.1 \ldots 30 \mathrm{~mm} / \mathrm{s}$ & \pm 6 \\
\hline \multirow{2}{*}{ Gearbox } & $V_{e}$ & $10 \ldots 1000$ & $0.1 \ldots 30 \mathrm{~mm} / \mathrm{s}$ & \pm 6 \\
\cline { 2 - 5 } & $a_{p}$ & $300 \ldots 10000$ & $0.1 \ldots 200 \mathrm{~m} / \mathrm{s}^{2}$ & \pm 6 \\
\hline \multirow{2}{*}{ Boring lock } & $V_{e}$ & $10 \ldots 1000$ & $0.1 \ldots 30 \mathrm{~mm} / \mathrm{s}$ & \pm 6 \\
\cline { 2 - 5 } & $a_{p}$ & $300 \ldots 10000$ & $0.1 \ldots 200 \mathrm{~m} / \mathrm{s}^{2}$ & \pm 6 \\
\hline
\end{tabular}

In operation, the frequency of subsequent control measurements is set after the evaluation and prediction of technical condition of the auger equipment. The maximum interval between measurements, depending on the results of the last control measurement was adopted no more: requires action - 7 days; warning - 1 month; permissible and acceptable renovated - 3 months [15].

Analysis of the spectrum of the vibration signal received on the bearing unit auger installation showed that the most probable defects are: shells, cracks, the wear of the rolling elements, distortions, cage destruction and violation of the bearing lubrication. All of these lesions cause an increased level of vibration at the nodes of auger equipment and untimely their elimination could lead to accidents-Term failure, which in turn will result in costly repairs and reduce the manufacturer-of works on the construction of a horizontal well.

This is caused by the imperfection of the design of the drilling of the lock case. During operation, the housing and depressurization occurs ingress of degradation products, which leads to jamming and bearings to more intensive percolation passing processes.

To improve performance, reduce mechanical vibrations and negative effect of vibration on components rotationally feeder auger wave-us in the department of mining machines and complexes of the Kuzbass State Technical University designed bearing unit (fig. 6), which allows to eliminate of foregoing shortcomings due to the use of this design in the radial ball bearings with the AFZ.

Fig. 7 shows a comparison of vibration levels on the bearing units in the construction of which used traditional design bearings and bearings with the AFZ. 

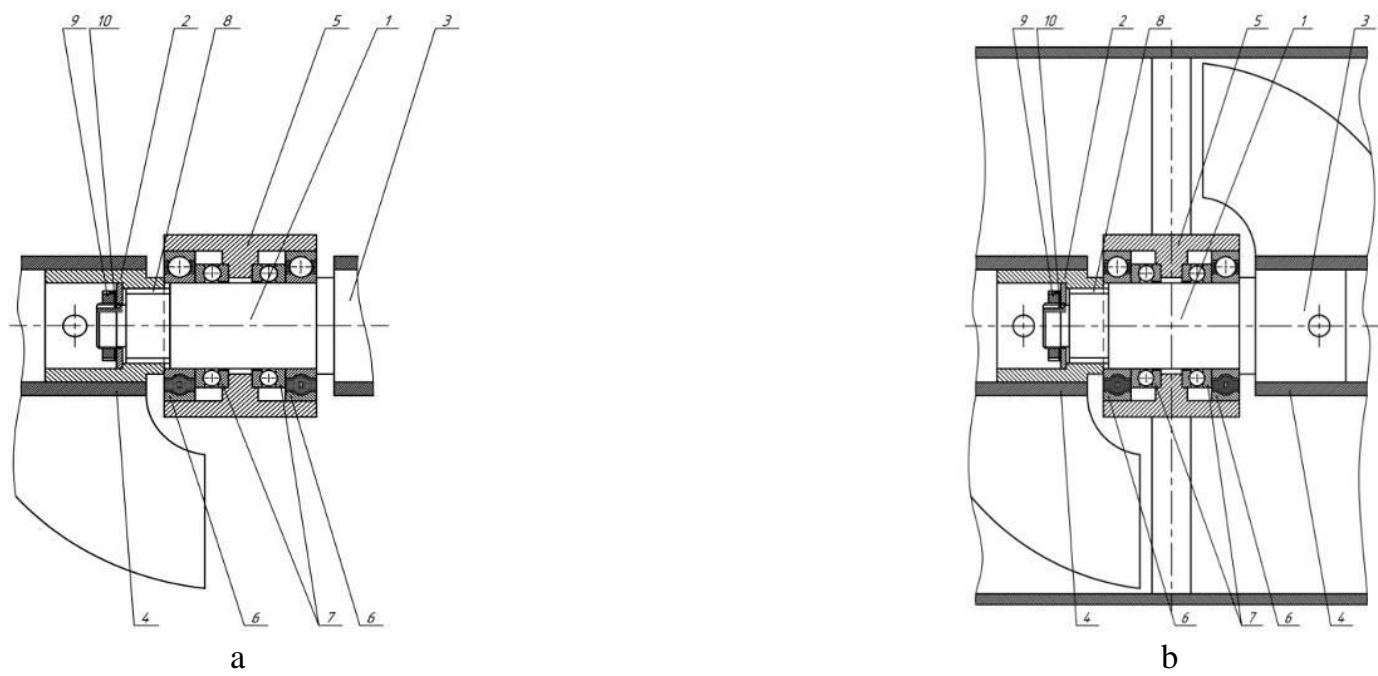

Fig. 6. New bearing units: (a) drilling lock unit; (b) sectional drilling tool unit

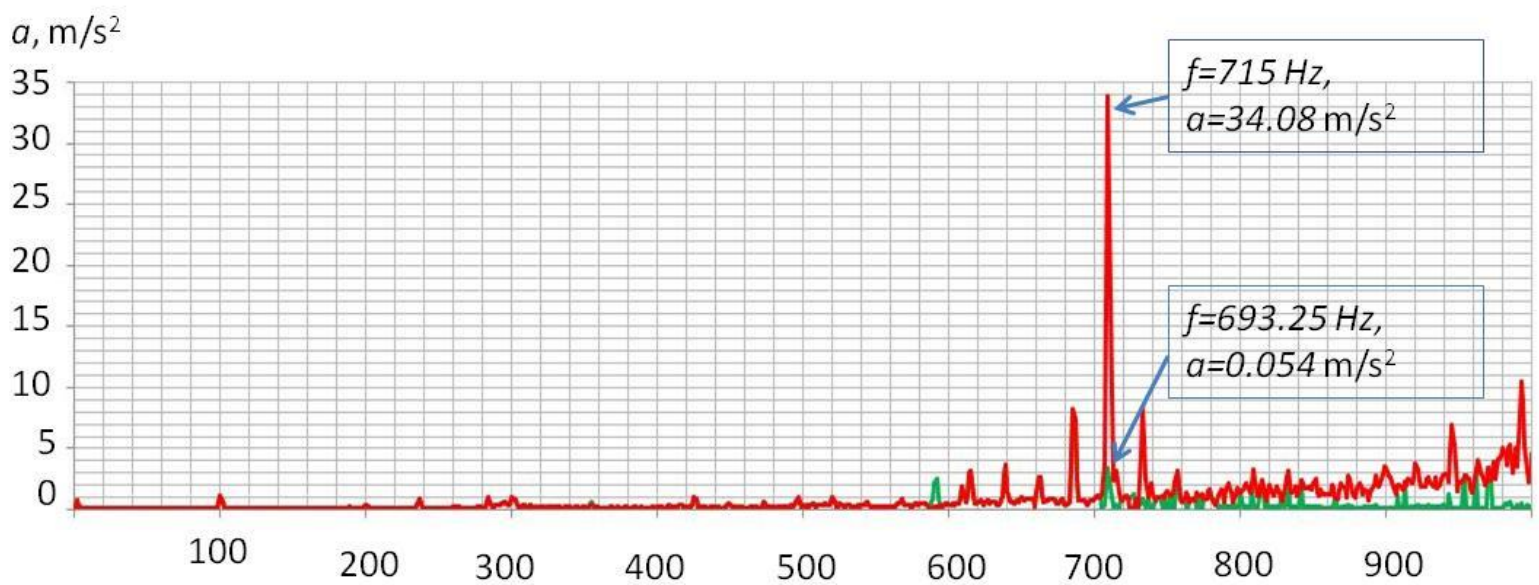

Fig. 7. The result of measuring the vibration level on the bearing unit, new conventional bearings and radial bearings with the AFZ

As can be seen from fig. 7 peak vibration levels using bearings with the AFZ is significantly lower than with conventional bearings.

\section{CONCLUSIONS}

The studies have shown that the use of radial bearings with AFZ without end caps in the mounting groups of the rotary feeder and auger tool for two-stage drilling of horizontal boreholes restricts getting the degradation products in the internal space in the moving parts of bearings, and reduces the level of vibration in the bearing assembly of the tool joint. In addition, it increases the service life of bearings supports in areas inaccessible for maintenance and repairs resulting in reduced labor intensity, energy and financial costs.

\section{ACKNOWLEDGMENT}

The authors thank the staff of the departments of mining machines and systems and information and automated production systems of the Kuzbass State Technical University. The authors also express their sincere appreciation and gratitude to A.A. Khoreshok and B.L. Guericke for personal contribution and support.

\section{REFERENCES}

[1] Khoreshok A.A., Mametev L.E., Borisov A.Yu., Vorobev A.V. Stress state of disk tool attachment points on tetrahedral prisms between axial bits. Applied Mechanics and Materials. 2015. T. 770. C. 434-438.

[2] Khoreshok A.A., Mametev L.E., Borisov A.Yu., Vorobev A.V. Finite element models of disk tools with attachment points on triangular prisms. Applied Mechanics and Materials. 2015. T. 770. P. 429-433.

[3] Aksenov V.V., Timofeev V.Yu., Dronov A.A. FEM study of stress strain state of elements of harmonic gear drive with hollow shaft and intermediate rollers. Applied Mechanics and Materials. 2015. Vol. 770. P. 464-468.

[4] Aksenov V.V., Glazkov Yu.F., Kazantsev A.A. Determination of load performance of two bar girder lining to support the control zone. Applied Mechanics and Materials. 2015. Vol. 770. P. 551-560.

[5] Sadovets V.Yu., Beglyakov V.Yu., Aksenov V.V. Development of math model of geokhod bladed working body interaction with geoenvironment. IOP Conference Series: Materials Science and Engineering. 2015. Vol. 91. \# 1. P. 012085.

[6] Buyalich G.D., Buyalich K.G. Comparative analysis of the lip seal in hydraulic power cylinder. Applied Mechanics and Materials. 2015. Vol. 770. P. 402-406.

[7] Mametyev L.E. Development of executive bodies and tools for boom tunneling machines and auger machines. Vestnik Kuzbass. gosud. tehn. 
univ. 2015. \# 5. pp: 56-63.

[8] Klishin V.I., Guericke B.L., Guericke P.B. Preventive maintenance of drilling rigs: advantages and prospects]. Vestnik Kuzbass. gosud. tehn. univ. 2015. \# 5. pp: 64-69.

[9] Guericke B.L., Mametyev L.E., Drozdenko Y.V. Evaluation of the technical condition of auger machine vibration parameters. Mining equipment and electromechanics. 2015. \#7. pp: 28-31.

[10] Milovanov M.V., Gorelikov V.G., Nasonov M.Y., Monakhov V.N. The impact on the cycle life of metal structures mining machinery operating environment. Vestnik Kuzbass. gosud. tehn. univ.2014. \# 3. pp: $9-11$.

[11] Dubrovsky V.P., Tolstov A.E., Koturga V.P., Lyubimov O.V. Podshipnik kacheniya i sposob ego izgotovleniya [Bearing and its manufacturing method]. Certificate of authorship 1555558 (USSR).
[12] Lyubimov O.V. Improving resource of bearings of the screw composition of augers. Diss. ... Ph.D. Kemerovo, KuzSTU, 2012.

[13] Drozdenko Y.V. Formation Auger Equipment Reliability. Taishan Academic Forum - Project on Mine Disaster Prevention and Control. 2014. p. 171-176.

[14] Guericke B.L., Guericke P.B. Methodology of spectral masks for dynamic mining machinery equipment. Vestnik Kuzbass. gosud. tehn univ.. 2014. \# 4. pp: 20-22.

[15] Guericke B.L., ., Mametyev L.E., Drozdenko Y.V. Industrial diagnostic testing methods observation of auger equipment. Problems of industrial safety expertise in the Siberian Federal District Proceedings Vol.2. 2015. pp: 68-74. 